\title{
Experimental Study on the Dynamic Features of Cement-Stabilized Expansive Soil as Subgrade Filling of Heavy Haul Railway
}

\author{
Shang Yonghui ${ }^{1, *}$, Xu Linrong ${ }^{1}$, Zhao Ying $^{2}$, Huang Yali $^{1}$ and Ning-yi $\mathrm{OU}^{3}$ \\ ${ }^{1}$ School of Civil Engineering, Central South University, Changsha 410075, China \\ ${ }^{2}$ Institute of Architecture and Engineering, Huang Huai University, Zhumadian 463000, China \\ ${ }^{3}$ Center of International Affairs, CEKII Civil Engineering Co. Ltd., Kowloon, Hong Kong
}

Received 29 January 2017; Accepted 4 September 2017

\begin{abstract}
As a core layer of heavy haul railway subgrade, cement-stabilized expansive soil filling directly bears a hundred million times of repeated traffic load action, and its dynamic features under repeated dynamic load action determine subgrade working performances. However, relatively few studies focus on the dynamic features of cement-stabilized expansive soil by combining the load features of heavy haul railway. Under the engineering background of the stabilized expansive soil subgrade of the Menghua (Haolebaoji-Ji'an) heavy haul railway, a dynamic triaxial test under the condition of sustained vibration was conducted in this study to explore the laws of the dynamic features of cement-stabilized expansive soil under the influence of train load, including different dynamic stress values, confining pressures, and vibration frequencies. Change rules of parameters, such as dynamic strength, critical dynamic stress, dynamic elasticity modulus, and damping ratio of cement-stabilized expansive soil, were analyzed and compared with those of remolded plain expansive soil, lime-stabilized expansive soil, and coarse-particle filling. Results show the following: Compared with remolded plain expansive soil, the dynamic shear strength and modulus of cement-stabilized expansive soil increase by two to three times, and its critical dynamic stress increases by five to six times. Under the same conditions, the mean critical dynamic stress value of cement-stabilized expansive soil is 1.5-1.7 times greater than that of cement-containing coarse-particle filling, and the maximum value is 1.2 times greater than that of lime-stabilized expansive soil. Within a small strain range, the decreasing amplitude of dynamic modulus with strain reaches $70 \%$, whereas the increasing amplitude of damping ratio is $80 \%$. The working performance of cement-stabilized expansive soil used as subgrade filling of heavy haul railway satisfies requirements. The conclusions of this study provide a theoretical reference for the promotion and application of cement-stabilized expansive soil in practical heavy haul railway projects.
\end{abstract}

Keywords: Dynamic features, Cement-stablized expansive soil, Dynamic triaxial test, Heavy haul railway

\section{Introduction}

Given its considerable cargo transportation capacity and significant economic and social benefits, the heavy haul railway has become the main development direction of freight railway in various countries [1]. The $12^{\text {th }}$ Five-year Plan of China has included heavy haul railway in the preferential theme of National Program for Long- and Medium-Term Scientific and Technological Development and the independent innovation field of The 12th Five-year Plan for Railway Technological Development [2]. The $13^{\text {th }}$ Five-year Plan of China will complete eight horizontal and nine vertical network patterns of heavy haul railway transportation, and the total mileage will reach $30,000 \mathrm{~km}$ at the appointed time [3]. Overcoming the key technical problems that restrict heavy haul railway development is necessary to meet the national rapid development requirement for heavy haul railways.

Compared with countries with advanced heavy haul railway development, such as America, Russia, and

\footnotetext{
*E-mail address: mlpeter@163.com

ISSN: $1791-2377$ @ 2017 Eastern Macedonia and Thrace Institute of Technology. All rights reserved. doi:10.25103/jestr.106.18
}

Australia, heavy haul railway development in China is relatively lagging behind [4]. At present, Chinese emphasis in research on newly built heavy haul railway projects is mainly placed on project design and technical promotion and innovation during the construction process. However, studies on stress state and long-term performance of subgrade structure after a long-term operation are clearly insufficient [5]. As train load increases, higher requirements for subgrade structural strength and deformation have been proposed for heavy haul railways [6]. As a core layer of subgrade structure, whether the subgrade bed can bear the effect of long-term dynamic load of trains has always been a core technical problem in engineering circles. Thus, investigating the dynamic features of subgrade filling is of considerable significance to the assessment of the working performance of the railway subgrade.

The main pathway for studies on soil dynamic features is still the dynamic triaxial test. Seed et al. [7] studied the development pattern of accumulated deformation of sandy soil with pore pressure and vibration times. Xie et al. [8] analyzed influences of factors, such as confining pressure, dynamic stress, and drainage conditions, on accumulated deformation of remolded viscous silty soil on the basis of the study of Seed. On the basis of the previously mentioned studies, Luo et al. [9] researched the evolution status of 
accumulated deformation of high-speed railway subgrade filling. Under the engineering background of heavy haul railway in Suhuang, China, Leng et al. [10] studied the dynamic features of group A subgrade filling.

China does not currently have any practices or experiences in building heavy haul railway on expansive soil foundation. Previous studies on the dynamic features investigation of the stabilized expansive soil of heavy haul railway are relatively few. Therefore, under the engineering background of stabilized expansive soil subgrade of Menghua heavy haul railway, indoor dynamic triaxial test data were used to systematically study the dynamic features of cement-stabilized expansive soil as subgrade filling.

\section{State of the art}

With features such as swelling and softening after water absorption and shrinkage and seasoning crack after water loss [12], expansive soil is widely distributed within the global scope and is recognized as disastrous soil in engineering circles [13]. Japanese scholars believe that expansive soil is a kind of "heavy in hand soil," [14] American scholars call it "soil with many problems," [15] and Chinese scholars provided a trick name "cancer in the engineering circles" [16]. China encountered the destructive problem of expansive soil in the Chengdu-Chongqing Railway project for the first time in the 1950s [17]. According to previous railway construction practices, the serviceability rate of existing railway subgrades in expansive soil region is only $25 \%$ [18]. Initially, estimated global economic loss due to expansive soil subgrade projects exceeded 10 billion dollars every year [19]. The problem of expansive soil engineering has become an international reshearch project [20].

Chinese and foreign scholars have conducted many experimental studies on the engineering properties of expansive soil, and the main contents include the following: (1) Mineral composition. Numerous experimental results of $\mathrm{X}$-ray diffraction indicate that expansive soil mainly includes montmorillonite [21], illite [21], quartz [22], and other minerals. (2) Microstructure. Scanning electron microscopy (SEM) test shows that illite and kaolinite in expansive soil microstructure are foliated [23], whereas quartz is granular [24]. (3) Expansibility. Expansibility is the main source of engineering problems caused by expansive soil [25]. Pitthaya [26] and Zha [27] et al. conducted many experimental studies on expansibility. Expansive soil is classified into three types according to its expansibility: strong, moderate, and weak. (4) Other physical-mechanical indexes. Numerous experimental results indicate that expansive soil cannot be directly used as subgrade construction filling, and expansive soil in railway engineering is classified as D-type subgrade filling [28]. Chemical improvement methods, such as lime or cement, are typically used in projects to make expansive soil indexes reach the design level of subgrade filling.

Foreign studies on chemically improved expansive soil started early. Jones completed a report on expansive soil improvement by lime and cement in 1958 [29], and Fahoum et al. [30] analyzed dynamic features of expansive soil after lime treatment in 1966. Petry et al. [31] reviewed disposition principles and methods of expansive soil engineering in Europe and America over nearly 60 years on the $150^{\text {th }}$ anniversary of the American Society of Civil Engineers, most of which were concentrated on lime-stabilized expansive soil. In the recent 10 years, the main study fields of lime-stabilized expansive soil in domestic and foreign countries are as follows: (1) control of subgrade filling indexes, such as lime content, moisture content, and compactness; (2) optimization of filling process and evaluation of construction quality; and (3) dynamic features of fillings. On the basis of triaxial and SEM tests, Wang et al. [32] discussed the dynamic features of unsaturated limestabilized expansive soil from microscopic and macroscopic angles. Mao et al. [33] concluded a correlation between accumulated plastic strain and load action frequency of limestabilized expansive soil. Zhou et al. [34] analyzed the influences of moisture content and vibration frequency on the critical dynamic stress of lime-stabilized expansive soil. Yang et al. [35] combined critical dynamic stress method to evaluate the feasibility of lime-stabilized expansive soil used as subgrade filling for a high-speed railway. Cheng et al. [36] explored the influence of drying-wetting cycle on the dynamic features of cement-stabilized expansive soil as the filling of high-speed railway.

Overall, among the abovementioned study results on the aspects of the dynamic features of lime and cementstabilized expansive soil, engineering backgrounds are mostly highway, common railway, or high-speed railway, but very few findings on heavy haul railway have been reported. The line from Sanmenxia to Jingmen on Menghua heavy haul railway, which is newly built in China, lies in the area of Nanyang Basin, which is a typical expansive soil region. The stabilized expansive soil filling area is approximately $1,581 \times 104 \mathrm{~m}^{3}$, which provides fundamental conditions for this study. Therefore, Dashanzhai expansive soil in Dengzhou City was selected for studying the dynamic features of improved expansive soils with $3 \%$ and $5 \%$ cement content, which were then compared with limestabilized expansive soil and coarse-particle filling containing cement, respectively. The results of this study can provide a theoretical reference for the promotion and application of cement-stabilized expansive soil in practical heavy haul railway projects.

\section{Methodology}

\subsection{Soil sample selection and improvement}

Soil samples were selected from the Dashanzhai borrow area near Dengzhou City. The basic physical and mechanical parameters of soil samples are shown in Table 1. P.O 42.5 silicate cement was used to improve soil samples, and cement contents were $3 \%$ and $5 \%$. Cement index parameters were selected in this test as shown in Table 2. The physical and mechanical parameters after expansive soil improvement adulterated with cement are shown in Table 3.

\subsection{Dynamic loading system of the test}

DDS-70 microcomputer interface technique electromagnetic vibration triaxial test system was selected in this test. Considering features of train load action, single-width vibration sine waves were used for loading, and frequencies were taken as 1 and $5 \mathrm{HZ}$. Loading stress amplitude was controlled within $20-250 \mathrm{kPa}$, while extreme difference was controlled at approximately $10-20 \mathrm{kPa}$ during the step-bystep loading process. 
Shang Yonghui, Xu Linrong, Zhao Ying, Huang Yali and Ning-yi OU/

Journal of Engineering Science and Technology Review 10 (6) (2017) 136-145

Table 1. Basic physical and mechanical parameters of soil samples (Dashanzhai)

\begin{tabular}{l|l|l|l}
\hline Natural water content/\% & Liquid limit/\% & Friction angle/ & Cation exchange capacity/(mmol/kg) \\
\hline $20.0-27.5$ & $36.9-50.3$ & $18-22$ & $276-390$ \\
Soil natural density $/\left(\mathrm{g} / \mathrm{cm}^{3}\right)$ & Plastic limit $/ \%$ & Cohesive force $/ \mathrm{kPa}$ & Montmorillonite content $\%$ \\
$1.75-2.01$ & $23.7-27.9$ & $38-46$ & $22-28$ \\
Coefficient of compressibility/ $\mathrm{MPa}^{-1}$ & Plasticity Index & Free swelling ratio/\% & Expansion capacity without load \\
$0.19-0.23$ & $13.2-21.4$ & $55-73$ & $15-30$ \\
Compression modulus $/ \mathrm{MPa}$ & Liquidity index & Expansion force/ $\mathrm{kPa}$ & \\
$7.22-9.01$ & $0.04-0.31$ & $27-129$ & \\
\hline
\end{tabular}

Table 2. Cement index parameters (P.O 42.5)

\begin{tabular}{|c|c|c|c|c|c|c|}
\hline \multicolumn{2}{|c|}{ Compressive strength/MPa } & \multicolumn{2}{|c|}{ Flexural strength /MPa } & \multicolumn{2}{|l|}{ Setting time } & \multirow{2}{*}{\begin{tabular}{|l|} 
Fineness $/ \%$ \\
$0.08 \mathrm{~mm}$ square hole
\end{tabular}} \\
\hline $3 \mathrm{~d}$ & $28 \mathrm{~d}$ & $3 \mathrm{~d}$ & $28 \mathrm{~d}$ & initial setting & final setting & \\
\hline 30.2 & 50.4 & 5.5 & 7.9 & $1 \mathrm{~h} 30 \mathrm{~min}$ & $1 \mathrm{~h} 05 \mathrm{~min}$ & 1.1 \\
\hline
\end{tabular}

Table 3. Physical and mechanical parameters of cement-stabilized expansive soil (average value)

\begin{tabular}{l|l|l|l|l}
\hline Content & Optimum water content/\% & Liquid limit/\% & Plastic limit/\% \\
\hline $3 \%$ & 14.9 & 42.4 & 27.9 & Friction angle/ \\
$5 \%$ & 15.3 & 41.4 & 29.5 & 27.6 \\
Content & Unconfined compressive strength/kPa & Free swelling ratio/\% & Expansion force/kPa \\
$3 \%$ & 335 (Saturated sample) & 32 & 14 & Cohesive force/kPa \\
$5 \%$ & 852 (Saturated sample) & 23 & 1 & 139 \\
\hline
\end{tabular}

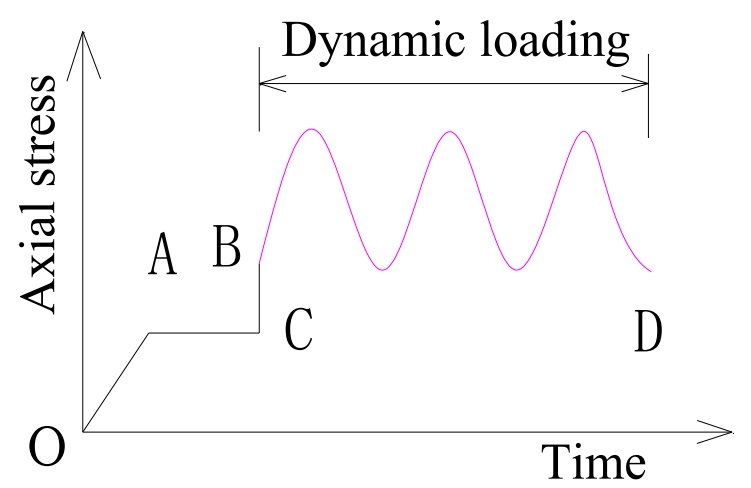

Fig. 1. Loading curves

The loading curve from Fig. 1 shows the following: The OA segment expresses the pressure in the consolidation phase, and its size is equal to the gradually increasing confining pressure; meanwhile, the axial pressure of the sample is equivalent to the overburden pressure borne by the soil sample at the subgrade bed layer; the BC segment expresses the unchanged confining pressure, and axial static pressure is applied to simulate train static load (additional load) borne by the soil sample at the subgrade bed layer; and the CD segment expresses the application of axial dynamic stress amplitude to simulate the dynamic load action of train operation on the subgrade surface layer.

\subsection{Dynamic triaxial test contents}

Combined with Literature [10] and [37], confining pressures in the test were selected as 14,30 , and $60 \mathrm{kPa}$ to simulate lateral pressure environment within a $3 \mathrm{~m}$ range of the subgrade bed of the heavy haul railway. The samples were cylinders with a diameter of $39.1 \mathrm{~mm}$ and a height of $80 \mathrm{~mm}$ Sample preparation was executed in strict accordance with Geo-technical Testing Regulations on Railway Engineering (TB10102) and Geo-technical Testing Regulations (SL237). The compactness degree of heavily compacted sample preparation was $95 \%$. The maintenance time was $28 \mathrm{~d}$, and the consolidation ratio was 1 . The failure criteria of the soil samples were as follows: accumulated strain reached $15 \%$; when variables smaller than $0.1 \mathrm{~mm}$ lasting $15 \mathrm{~min}$ continuously occurred three times during the infrangibility test, the test would be terminated. Test contents are presented in Table 4, and the testing process is demonstrated in detail in Fig. 2.

Table 4. Test contents

\begin{tabular}{l|l|l|l}
\hline Category & Dry density & $f / \mathbf{H Z}$ & $\sigma_{3} / \mathbf{k P a}$ \\
\hline Remolded plain expansive soil & $1.67 \mathrm{~g} / \mathrm{cm}^{3}$ & 1 & 30,60 \\
Expansive soil improved with & $1.72 \mathrm{~g} / \mathrm{cm}^{3}$ & 1 & 30,60 \\
$3 \%$ cement content & 5 & $15,30,60$ \\
Expansive soil improved with & $1.72 \mathrm{~g} / \mathrm{cm}^{3}$ & 1 & $15,30,60$ \\
$5 \%$ cement content & 5 & $15,30,60$ \\
\hline
\end{tabular}

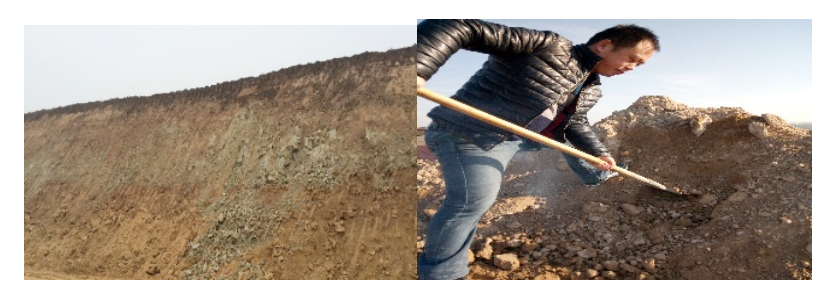

(1) Soil site (Dashanzhai)

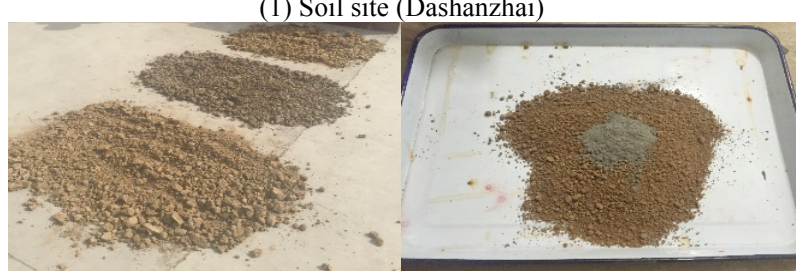

(2) Drying and cement mixing

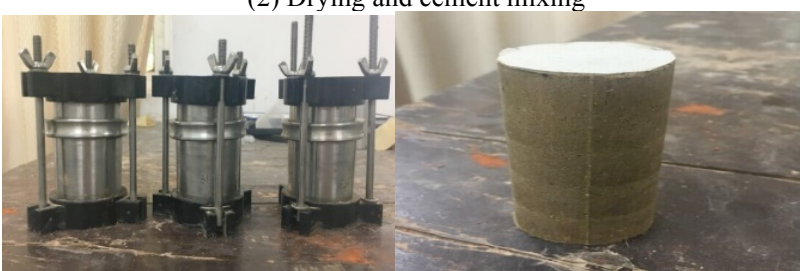

(3) Sample

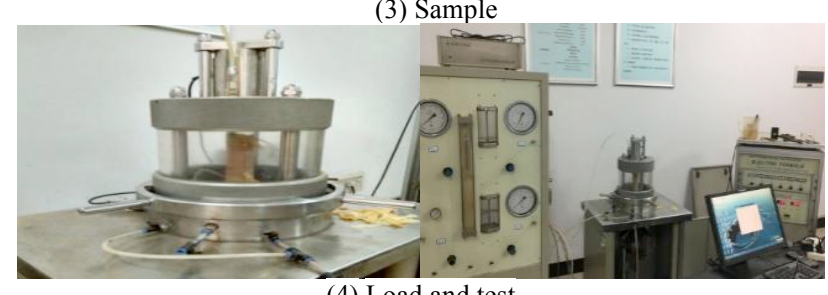

(4) Load and test

Fig. 2. Testing process 
Shang Yonghui, Xu Linrong, Zhao Ying, Huang Yali and Ning-yi OU/

Journal of Engineering Science and Technology Review 10 (6) (2017) 136-145

\section{Result Analysis and Discussion}

\subsection{Dynamic strength}

Dynamic strength refers to the dynamic stress amplitude required by the soil body to reach a certain failure criterion after $N$ times repeated action of a certain dynamic load.

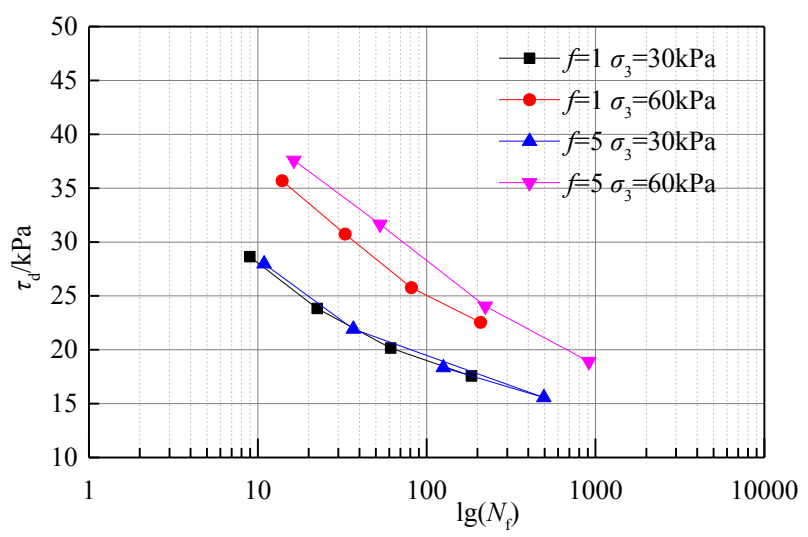

(1) Remolded plain expansive soil

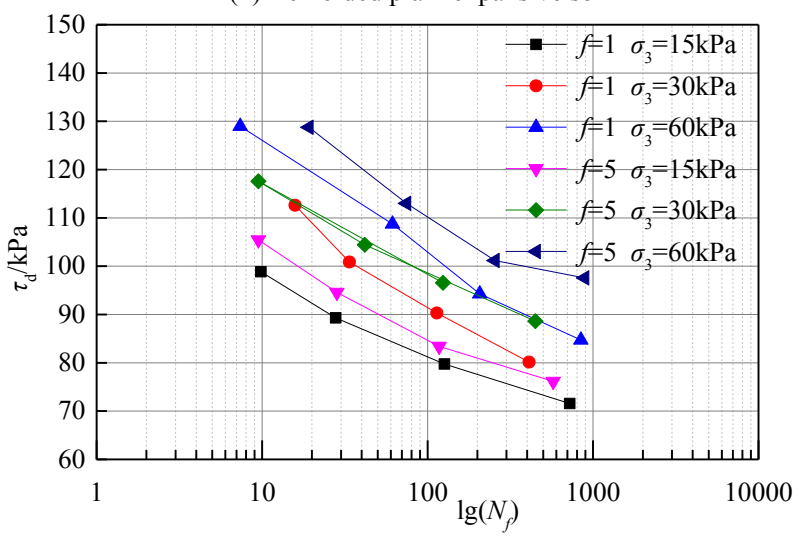

(2) Expansive soil stabilized with 3\% cement content

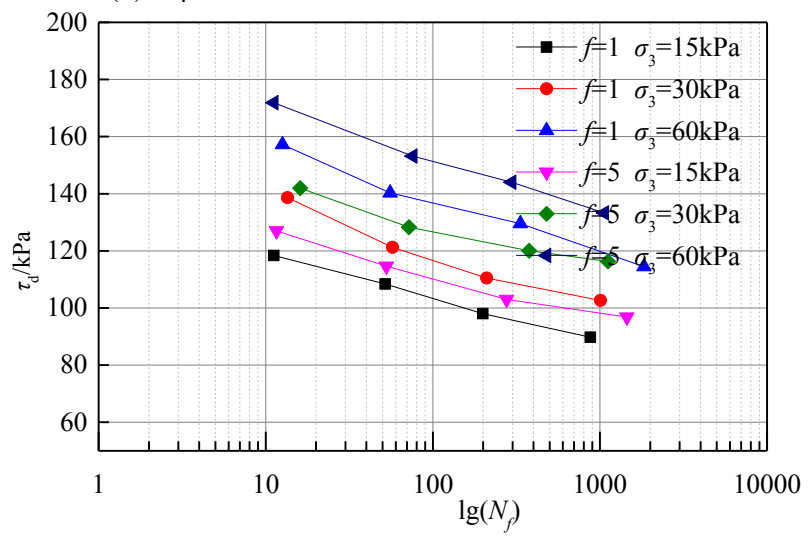

(3) Expansive soil stabilized with 5\% cement content

Fig. 3. $\tau_{\mathbf{d}}-\lg \left(N_{f}\right)$ Curves

Fig. 3 shows that cement addition significantly improves the dynamic shear strength of expansive soil. Compared with those of remolded plain expansive soil, the dynamic shear strengths of expansive soils stabilized with $3 \%$ and $5 \%$ cement content increase by two to three times. Dynamic shear strength has an evident reinforcing trend as confining pressure and consolidation ratio increase, which indicates that the dynamic shear strengths of remolded plain expansive soil and cement-stabilized expansive soil are mainly related to soil properties and initial stress state. Compared with confining pressure, the influence of frequency on dynamic strength is weaker, and the dynamic strength of cement-stabilized soil has a weak increasing trend with frequency.

\subsection{Critical dynamic stress}

According to test results, $\varepsilon_{p}-\lg N$ curves that show the development of accumulated strain with vibration times are illustrated. $\varepsilon_{p}-\lg N$ curvilinear trend can be divided into three types: stable, failure, and critical types. Dynamic stress between stable and failure types is called "critical dynamic stress.” Thus, critical dynamic stress is an interval value.

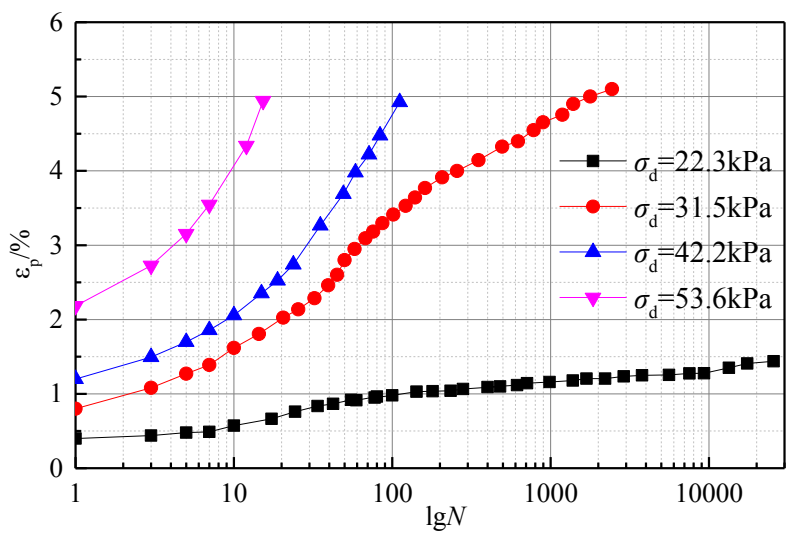

(1) Remolded plain expansive soil

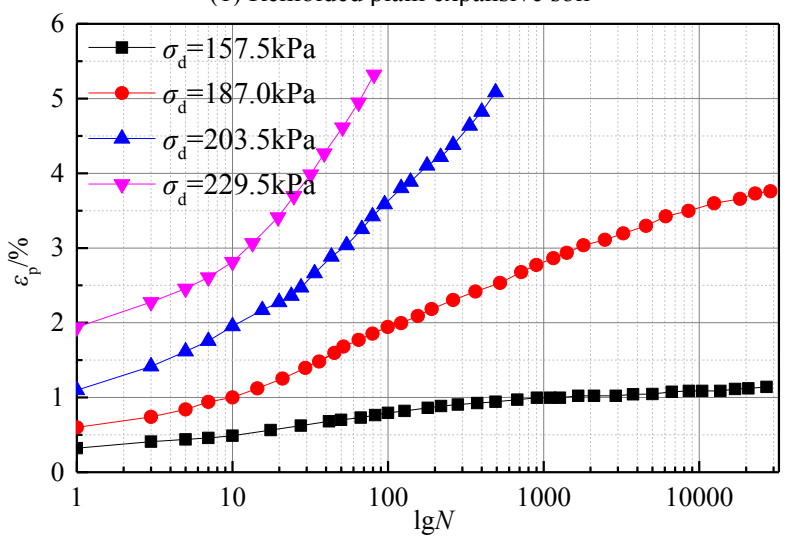

(2) Expansive soil improved with 3\% cement content

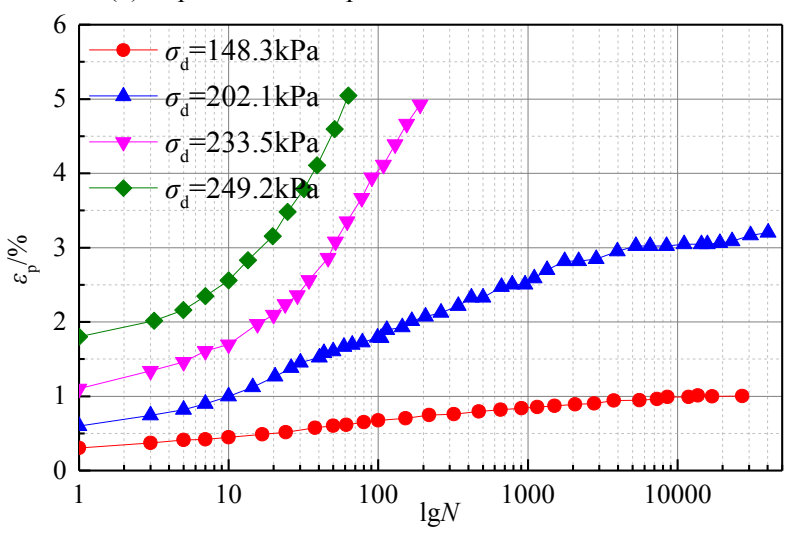

(3) Expansive soil improved with 5\% cement content Fig. 4. $\varepsilon_{p}-\lg N$ Curves $\left(\sigma_{3}=30 \mathrm{kPa}, f=1 \mathrm{HZ}\right)$

Combining the curves in Fig. 4, the critical dynamic stresses of remolded plain expansive soil and expansive soils stabilized with $3 \%$ and $5 \%$ cement content, respectively, are calculated (details are presented in Table 5).

Table 5 shows that the range of critical dynamic stress of remolded plain expansive soil is $21.6-34.9 \mathrm{kPa}$, and the 
Shang Yonghui, Xu Linrong, Zhao Ying, Huang Yali and Ning-yi OU/

Journal of Engineering Science and Technology Review 10 (6) (2017) 136-145

mean value is $28.25 \mathrm{kPa}$. The range of critical dynamic stress of expansive soil stabilized with $3 \%$ cement content is $148.8-233.1 \mathrm{kPa}$ and the mean value is $190.95 \mathrm{kPa}$, while those of expansive soil stabilized with $5 \%$ cement content are $145.6-249.7$ and $197.65 \mathrm{kPa}$. The mean critical dynamic stress values of expansive soils stabilized with $3 \%$ and $5 \%$ cement content are 6.8 and 7.0 times greater than that of remolded plain expansive soil, respectively. Compared with the critical dynamic stresses of remolded plain expansive soil, those of cement-stabilized expansive soils correspondingly increase by five to six times. The increase degree of critical dynamic stress with cement content and confining pressure is large, while the degree has a weak decrease trend as frequency increases.

Table 5. Critical dynamic stress

\begin{tabular}{l|c|l|l|l}
\hline \multicolumn{1}{c|}{ Category } & $\sigma_{3}$ & $\boldsymbol{f}$ & $\begin{array}{c}\text { Critical dynamic } \\
\text { stress }\end{array}$ & Mean value \\
\hline & $30 \mathrm{kPa}$ & $1 \mathrm{HZ}$ & $22.3-31.5 \mathrm{kPa}$ & $26.90 \mathrm{kPa}$ \\
Remolded plain & $60 \mathrm{kPa}$ & $1 \mathrm{HZ}$ & $28.6-34.9 \mathrm{kPa}$ & $31.75 \mathrm{kPa}$ \\
expansive soil & $30 \mathrm{kPa}$ & $5 \mathrm{HZ}$ & $21.6-30.8 \mathrm{kPa}$ & $26.20 \mathrm{kPa}$ \\
& $60 \mathrm{kPa}$ & $5 \mathrm{HZ}$ & $27.2-33.7 \mathrm{kPa}$ & $30.45 \mathrm{kPa}$ \\
\hline & $15 \mathrm{kPa}$ & $1 \mathrm{HZ}$ & $151.2-185.7 \mathrm{kPa}$ & $168.45 \mathrm{kPa}$ \\
Expansive soil & $30 \mathrm{kPa}$ & $1 \mathrm{HZ}$ & $157.5-203.5 \mathrm{kPa}$ & $180.50 \mathrm{kPa}$ \\
improved with & $60 \mathrm{kPa}$ & $1 \mathrm{HZ}$ & $182.3-233.1 \mathrm{kPa}$ & $207.70 \mathrm{kPa}$ \\
$3 \%$ cement & $15 \mathrm{kPa}$ & $5 \mathrm{HZ}$ & $148.8-181.4 \mathrm{kPa}$ & $165.10 \mathrm{kPa}$ \\
content & $30 \mathrm{kPa}$ & $5 \mathrm{HZ}$ & $152.3-200.1 \mathrm{kPa}$ & $176.20 \mathrm{kPa}$ \\
& $60 \mathrm{kPa}$ & $5 \mathrm{HZ}$ & $180.6-229.6 \mathrm{kPa}$ & $205.10 \mathrm{kPa}$ \\
\hline & $15 \mathrm{kPa}$ & $1 \mathrm{HZ}$ & $142.5-208.1 \mathrm{kPa}$ & $175.30 \mathrm{kPa}$ \\
Expansive soil & $30 \mathrm{kPa}$ & $1 \mathrm{HZ}$ & $148.3-233.5 \mathrm{kPa}$ & $190.90 \mathrm{kPa}$ \\
improved with & $60 \mathrm{kPa}$ & $1 \mathrm{HZ}$ & $202.5-249.7 \mathrm{kPa}$ & $226.10 \mathrm{kPa}$ \\
$5 \%$ cement & $15 \mathrm{kPa}$ & $5 \mathrm{HZ}$ & $147.8-199.6 \mathrm{kPa}$ & $173.70 \mathrm{kPa}$ \\
content & $30 \mathrm{kPa}$ & $5 \mathrm{HZ}$ & $145.6-231.7 \mathrm{kPa}$ & $188.65 \mathrm{kPa}$ \\
& $60 \mathrm{k} \mathrm{Pa}$ & $5 \mathrm{HZ}$ & $201.5-246.2 \mathrm{kPa}$ & $223.85 \mathrm{kPa}$ \\
\hline
\end{tabular}

Test data were combined for regression analysis to further analyze the relationship between confining pressure and critical dynamic stress, as specifically shown in Fig. 5.

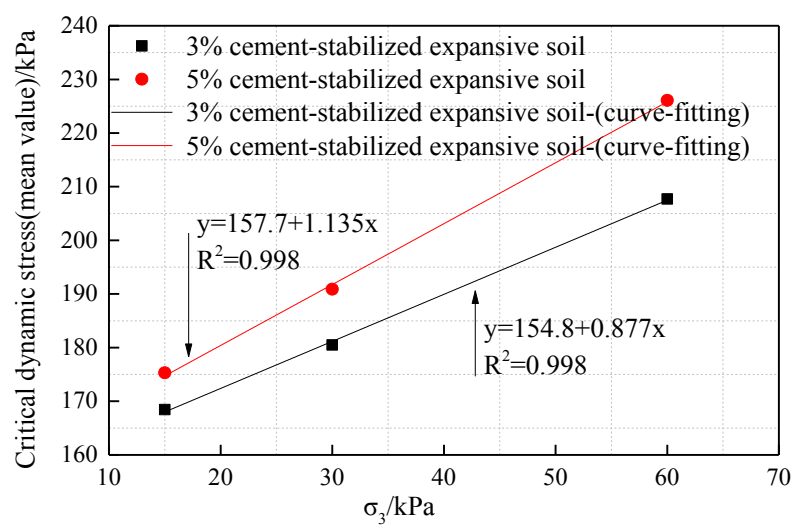

Fig. 5. Regression analysis between critical dynamic stress and confining pressure $(f=1 \mathrm{HZ})$

Fig. 5 shows that critical dynamic stress has a favorable linear correlation with confining pressure, and the correlation coefficients are all larger than 0.998. Therefore, critical dynamic stress can be deemed to present a linear growing trend as confining pressure increases. Considering the influence of confining pressure on critical dynamic stress, emphasis should be placed on the monitoring of the subgrade bed for accumulated deformation under dynamic load action. As a result of the shallow burial depth of the subgrade bed, the lateral confining pressure of the surrounding soil body is small, and its critical dynamic stress also decreases. By contrast, the subgrade bed bears most of the dynamic load action, thereby easily generating considerable accumulated deformation.

\subsection{Comparison of critical dynamic stresses of different types of fillings}

Under a high-speed railway project background, Literature [34] combined dynamic triaxial test to obtain the critical dynamic stress of expansive soil. Subgrade filling improved with $3 \%$ lime content at approximately $190 \mathrm{kPa}$, which was slightly smaller than that $(148.8-233.1 \mathrm{kPa})$ of $3 \%$ cementstabilized expansive soil. The maximum value of the latter was 1.2 times greater than that of the former.

Literature [10] combined TAJ-2000 large-scale dynamic triaxial tester from the national-level high-speed railway laboratory in Central South University to acquire the critical dynamic stress value of the cement containing coarseparticle soil of a heavy haul railway.

Table 6. Comparison of critical dynamic stress $(f=1 \mathrm{HZ})$

\begin{tabular}{l|l|l|l}
\hline \multicolumn{1}{c|}{ Category } & $\sigma_{3}$ & $\begin{array}{c}\text { Critical dynamic } \\
\text { stress }\end{array}$ & Mean value \\
\hline Expansive soil & $15 \mathrm{kPa}$ & $151.2-185.7 \mathrm{kPa}$ & $168.45 \mathrm{kPa}$ \\
improved with $3 \%$ & $30 \mathrm{kPa}$ & $157.5-203.5 \mathrm{kPa}$ & $180.50 \mathrm{kPa}$ \\
cement content & $60 \mathrm{kPa}$ & $182.3-233.1 \mathrm{kPa}$ & $207.70 \mathrm{kPa}$ \\
\hline Expansive soil & $15 \mathrm{kPa}$ & $142.5-208.1 \mathrm{kPa}$ & $175.30 \mathrm{kPa}$ \\
improved with $5 \%$ & $30 \mathrm{kPa}$ & $148.3-233.5 \mathrm{kPa}$ & $190.90 \mathrm{kPa}$ \\
cement content & $60 \mathrm{kPa}$ & $202.5-249.7 \mathrm{kPa}$ & $226.10 \mathrm{kPa}$ \\
\hline \multirow{2}{*}{ Coarse-grained soil } & $15 \mathrm{kPa}$ & $100-125 \mathrm{kPa}$ & $112.5 \mathrm{kPa}$ \\
& $30 \mathrm{kPa}$ & $100-125 \mathrm{kPa}$ & $112.5 \mathrm{kPa}$ \\
& $60 \mathrm{kPa}$ & $125-150 \mathrm{kPa}$ & $137.5 \mathrm{kPa}$ \\
\hline
\end{tabular}

The comparison results in Table 6 show that the critical dynamic stress of cement containing coarse-particle soil is smaller than that of cement-stabilized expansive soil. The mean critical dynamic stress values of $3 \%$ and $5 \%$ cement content-stabilized expansive soils are 1.5 and 1.6 times greater than that of cement containing coarse-particle soil, respectively, when the confining pressure is $15 \mathrm{kPa}$. The mean critical dynamic stress values of $3 \%$ and $5 \%$ cement content-stabilized expansive soils are 1.6 and 1.7 times greater than that of cement containing coarse-particle soil, respectively, when the confining pressure is $30 \mathrm{kPa}$. The mean critical dynamic stress values of $3 \%$ and $5 \%$ cement content-stabilized expansive soils are 1.5 and 1.6 times greater than that of cement containing coarse-particle soil, respectively, when the confining pressure is $60 \mathrm{kPa}$. Thus, the critical dynamic stresses of $3 \%$ and $5 \%$ cement contentstabilized expansive soils are 1.5-1.7 times greater than that of cement containing coarse-particle soil.

\subsection{Analysis of elasticity modulus and damping ratio}

At present, the hyperbolic model of Hardin et al. is used to calculate the dynamic elasticity modulus for soil stressstrain hysteresis curves, and Equation (1) is adopted for dynamic modulus calculation:

$$
E_{d}=\frac{\sigma_{d}}{\varepsilon_{d}}=\frac{1}{\frac{1}{E_{d \max }}+\frac{\varepsilon_{d}}{\sigma_{d \max }}}
$$

where $E_{d}$ is the dynamic elasticity modulus, $\sigma_{d}$ is the axial dynamic stress, $\varepsilon_{d}$ is the axial dynamic strain, and $E_{d \max }$ and $\sigma_{d \max }$ are the maximum axial dynamic elasticity modulus and maximum axial dynamic stress, respectively. 
When $a=1 / E_{d \max }$ and $b=1 / \sigma_{d \max }$, then:

$$
E_{d}=\frac{1}{a+b \varepsilon_{d}}
$$

where $a$ and $b$ are undetermined parameters that will be identified by the test, and dynamic elasticity modulus $E_{d}$ corresponding to any dynamic strain $\varepsilon_{d}$ can then be solved.

Damping ratio is an important parameter that features the mechanical properties of soil body and the ratio of actual damping coefficient to critical damping coefficient. The common calculation formula is shown in Equation (3):

$\lambda=\frac{A_{0}}{4 \pi A_{\mathrm{a}}}$

where $A_{0}$ is the area of hysteretic circle, and $A_{a}$ is the triangular area under simplified calculation. The damping ratio at any cycle can be solved through Equation (3).

The area $A_{0}$ of the hysteretic circle is generally small when the stress level is low, and the error is large when the damping ratio $\lambda$ is solved according to Equation (4). The damping ratio can be solved through simplified relational expression between the damping ratio and the dynamic elasticity modulus as follows:

$$
\lambda=\lambda_{\max }\left(1-\frac{E_{d}}{E_{d \max }}\right)
$$

where $\lambda_{\max }$ is the maximum damping ratio acquired through the test. The curve tends to be gentle when $\varepsilon_{d}>10^{-3}$, and asymptotic constant is taken as the maximum damping ratio under this state. The damping ratio within the entire strain range can be calculated according to the maximum damping ratio.

Figs. 6-8 show the $E_{d}-\varepsilon_{d}$ and $1 / E_{d}-\varepsilon_{d}$ curve charts of remolded plain expansive soil and expansive soils stabilized with $3 \%$ and $5 \%$ cement content, respectively.

Fig. 6 shows that the dynamic elasticity modulus of remolded plain expansive soil presents two-stage features as strain level increases: (1) Sharp drop stage. Within a small strain range of $0-0.002$, the dynamic elasticity modulus decreases as strain increases, and the decreasing amplitude reaches approximately $70 \%$. (2) Stable stage. The dynamic elasticity modulus tends to be stable when the strain value is larger than 0.002 due to a few elastic deformation parts in this stage, which are mainly manifested by plastic deformation. Moreover, available space for the decrease in dynamic elasticity modulus is insufficient.

Figs. 7 and 8 show that the change curve of the dynamic elasticity modulus of cement-stabilized expansive soil with strain level coincides with that of remolded plain expansive soil. Compared with that of plain expansive soil, the dynamic elasticity modulus of cement-stabilized expansive soil is larger. The dynamic elasticity moduli of expansive soils stabilized with $3 \%$ and $5 \%$ cement content are three to four times greater than that of remolded plain expansive soil under the same test conditions. As cement solidification effect results in an increased rigidity of stabilized expansive soil, the strain range in elastic deformation stage considerably decreases. Considering that accurately measuring strain value within $10^{-4}$ is difficult for the dynamic triaxial test, $E_{d}-\varepsilon_{d}$ curves cannot reflect the change trend in the elastic stage, which is mainly manifested by a decrease in the dynamic elasticity modulus with the increase in dynamic strain within the plastic deformation range.

Meanwhile, the regression of $1 / E_{d}-\varepsilon_{d}$ curves shows that correlation coefficients between remolded plain expansive soil and cement-stabilized expansive soil all exceed 0.97 , thereby indicating that the test data agree with the fitting curves; a small discreteness of test data leads to a high confidence level.

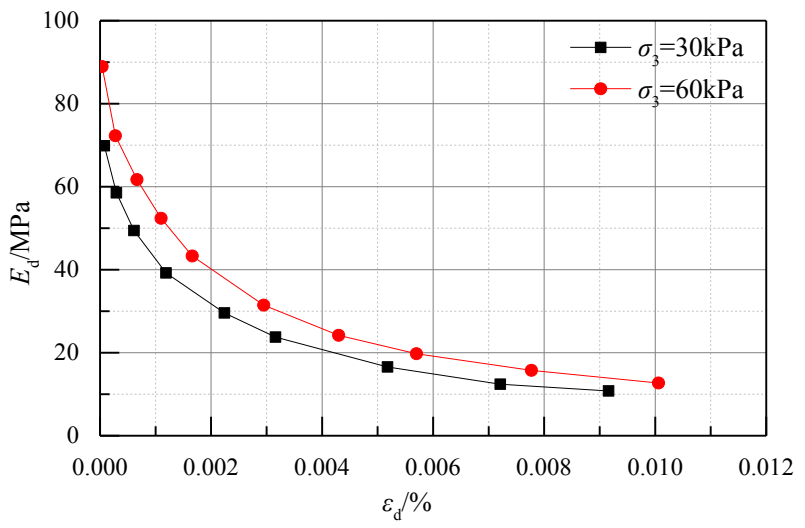

(1) $E_{d}-\varepsilon_{d}$ Curves

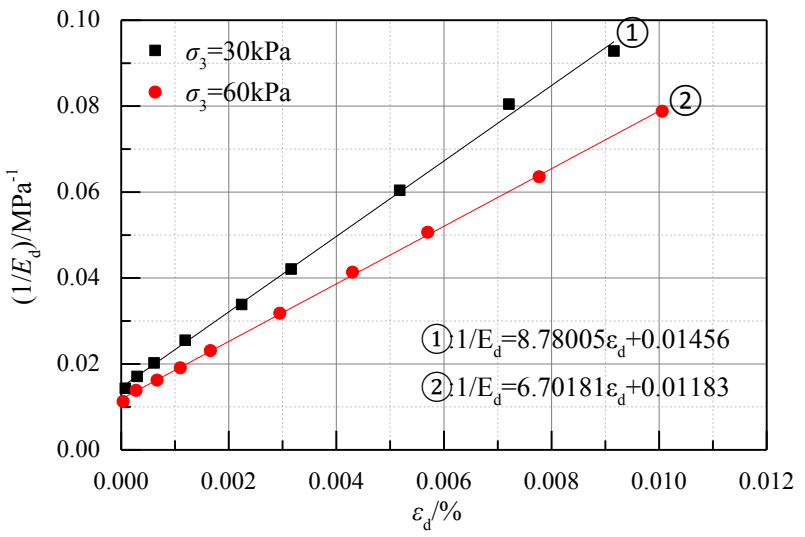

(2) $1 / E_{d}-\varepsilon_{d}$ Curves

Fig. 6. Remolded plain expansive soil ( $f=1 \mathrm{HZ}$ )

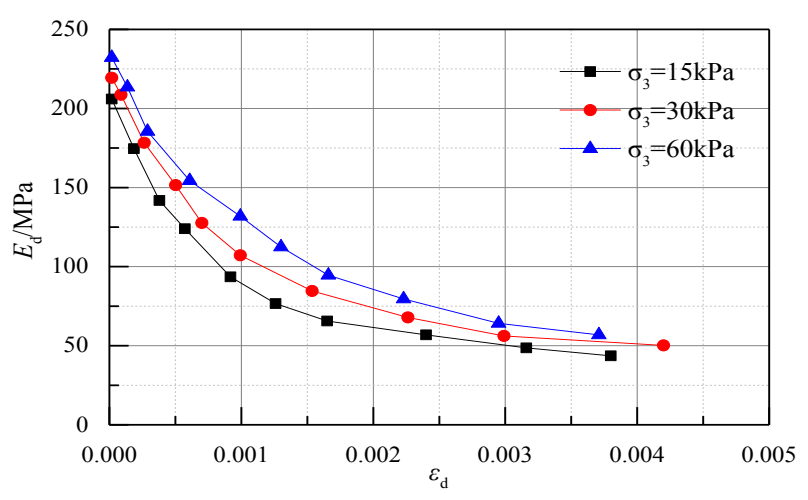

(1) $E_{d}-\varepsilon_{d}$ Curves 
Shang Yonghui, Xu Linrong, Zhao Ying, Huang Yali and Ning-yi OU/

Journal of Engineering Science and Technology Review 10 (6) (2017) 136-145

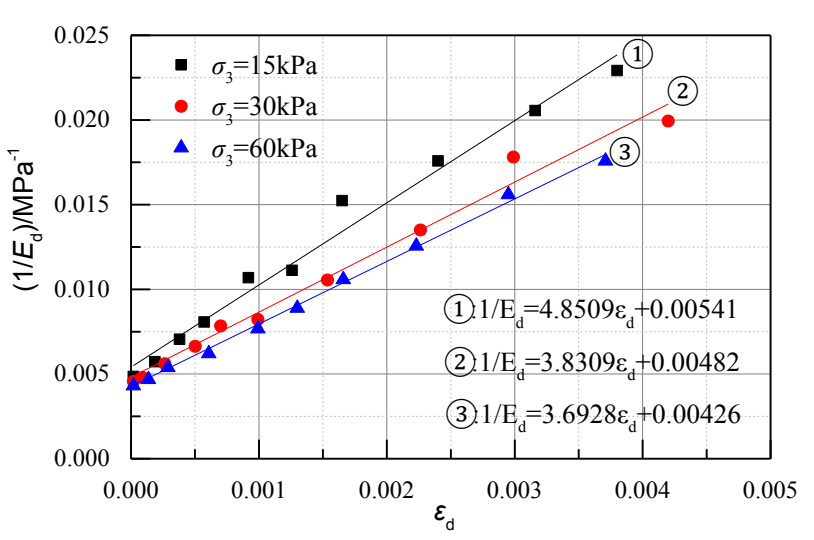

(2) $1 / E_{d}-\varepsilon_{d}$ Curves

Fig. 7. Expansive soil stabilized with $3 \%$ cement content ( $f=1 \mathrm{HZ}$ )

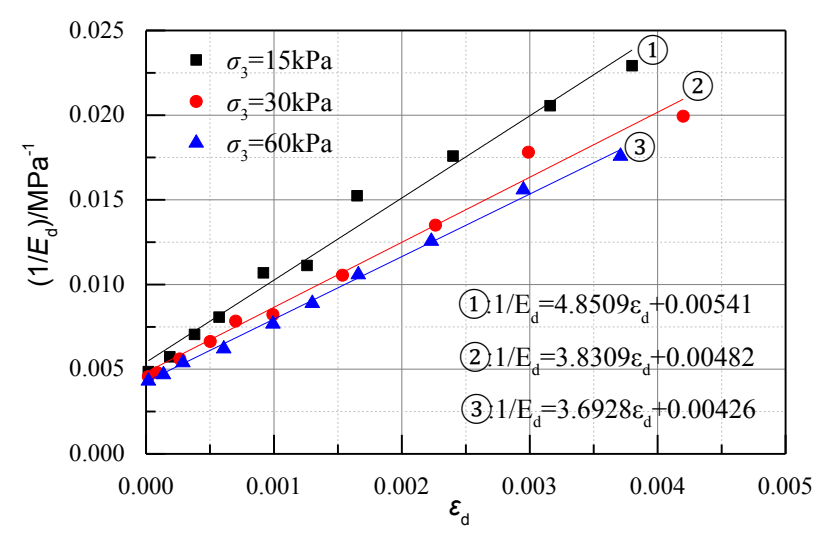

(1) $E_{d}-\varepsilon_{d}$ Curves

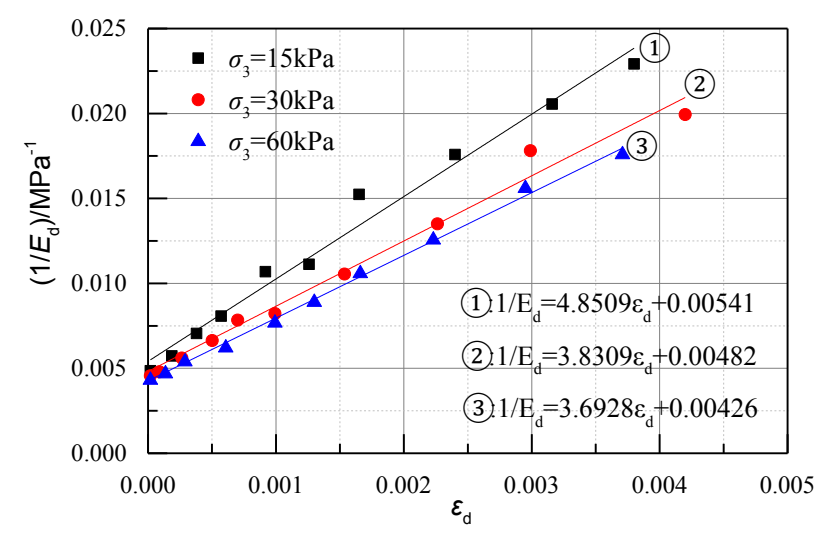

(2) $1 / E_{d}-\varepsilon_{d}$ Curves

Fig. 8. Expansive soil stabilized with $5 \%$ cement content $(f=1 \mathrm{HZ})$

Damping ratio is an important parameter that features the mechanical properties of soil body. Under reciprocal dynamic load action, the dynamic stress-strain hysteretic circle of soil body reflects the hysteresis of strain relative to stress due to damping influence. That is, the maximum value of dynamic stress does not synchronously appear with that of dynamic strain, and dynamic strain lags behind dynamic stress. Hence, a few scholars believe that this phenomenon is caused by energy consumption due to the internal frictional effect under soil body deformation, which reflects a gradual loss process of soil body energy under its internal resistance.

Fig. 9 shows that the damping ratio increases with strain due to the compaction effect between soil bodies as accumulated plastic deformation increases with the existence of a rupture plane. The propagation paths of stress waves will certainly reduce as rupture planes increase; hence, the damping ratio also increases. The damping ratio-strain curves of remolded plain expansive soil and cementstabilized expansive soil are divided into two stages: rapid increase stage and stable stage: (1) Rapid increase stage. For remolded plain expansive soil, the damping ratio within 0 0.004 strain range rapidly increases and can reach $80 \%$ of the maximum damping ratio. The damping ratio of cementstabilized expansive soil within $0-0.002$ strain range can reach $70 \%$ of the maximum damping ratio. (2) Stable stage. Increasing amplitudes of damping ratios with dynamic strain become small after the dynamic strain of remolded plain expansive soil reaches 0.004 and the strain of cementstabilized expansive soil reaches 0.002 . Then, both strains slowly approximate to the maximum damping ratio.

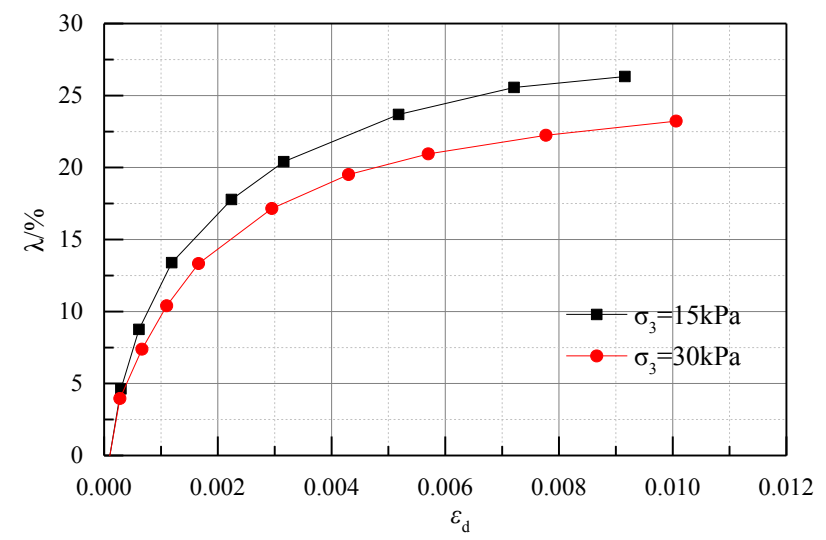

(1) Remolded plain expansive soil

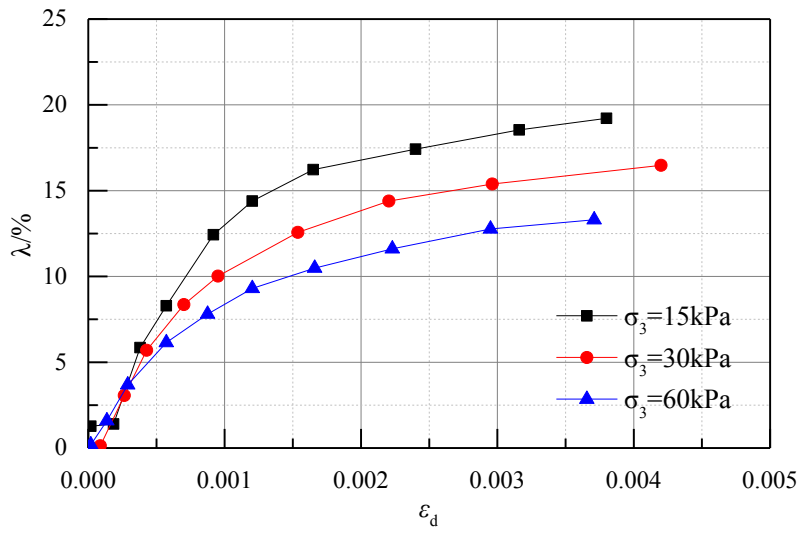

(2) Expansive soil stabilized with 3\% cement content

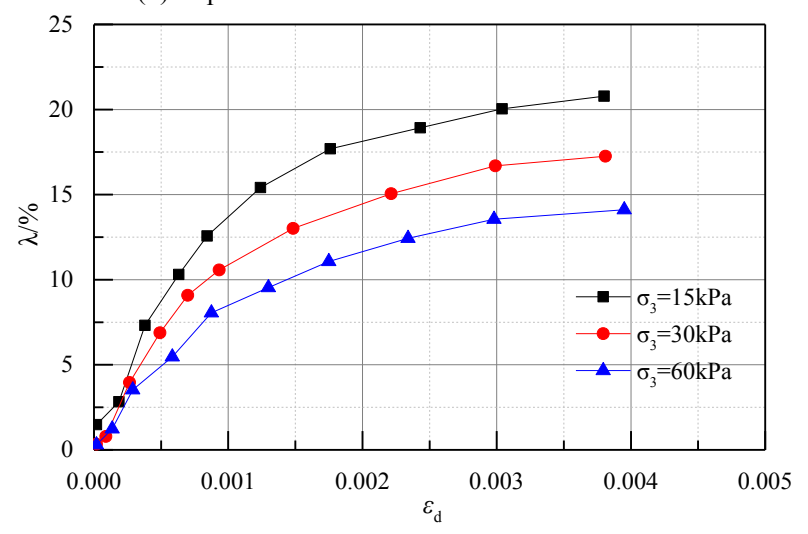

(3) Expansive soil stabilized with 5\% cement content

Fig. 9. $\lambda-\varepsilon_{\mathbf{d}}$ Curves $(f=1 \mathrm{HZ})$

Tables 7 and 8 summarize the maximum dynamic elasticity modulus and maximum damping ratio, respectively. The maximum dynamic elasticity moduli of remolded plain expansive soil and swell soils stabilized with $3 \%$ and $5 \%$ 
Shang Yonghui, Xu Linrong, Zhao Ying, Huang Yali and Ning-yi OU/

Journal of Engineering Science and Technology Review 10 (6) (2017) 136-145

cement content are 60-150, 180-340, and 240-350 MPa, and their maximum damping ratios are $18 \%-39 \%, 11 \%$ $30 \%$, and $10 \sim 29 \%$, respectively. Thus, cement addition can significantly improve the strength of expansive soil, whereas the change in damping ratio is relatively minor. An increase in the confining pressure has different influences on dynamic elasticity modulus and maximum damping ratio. The dynamic elasticity modulus increases with confining pressure, whereas the maximum damping ratio decreases with confining pressure. The maximum dynamic elasticity modulus and maximum damping ratio increase to different degrees as frequency increases.

Table 7. Maximum dynamic elasticity moduli

\begin{tabular}{l|l|l|l|l|l}
\hline $\boldsymbol{f} / \mathbf{H Z}$ & $\sigma_{3} / \mathbf{k P a}$ & $\begin{array}{l}\text { Remolded plain } \\
\text { soil/MPa }\end{array}$ & $\begin{array}{l}\text { expansive } \\
\text { Expansive soil stabilized with 3\% cement } \\
\text { content /MPa }\end{array}$ & $\begin{array}{l}\text { Expansive soil stabilized with 5\% cement } \\
\text { content /MPa }\end{array}$ \\
\hline \multirow{3}{*}{1} & 15 & 68.68 & 184.84 & 243.90 \\
& 30 & 84.53 & 207.47 & 270.27 \\
\hline \multirow{3}{*}{5} & 60 & 15 & 79.11 & 234.74 & 285.71 \\
& 30 & 102.25 & 215.05 & 270.27 \\
\hline
\end{tabular}

Table 8. Maximum damping ratio

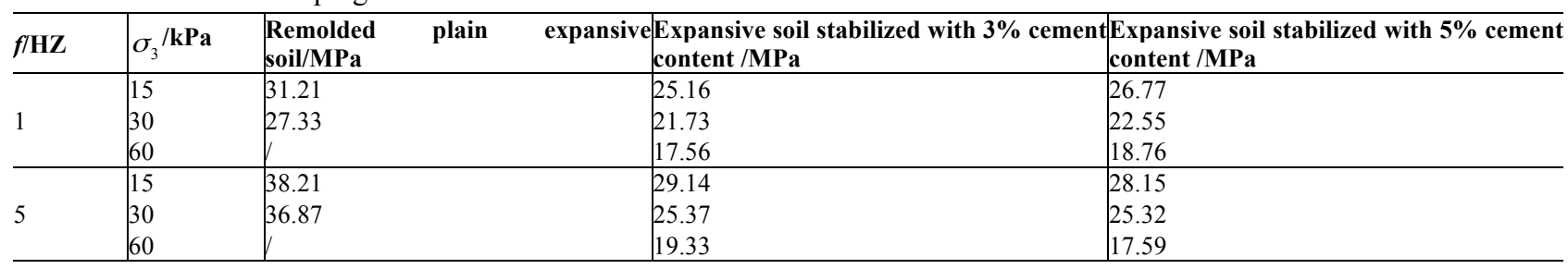

\subsection{Pavement performance of cement-stabilized expansive soil filling}

The subgrade filling at the surface layer (thickness $0.6 \mathrm{~m}$ ) of the foundation bed on the DK948+245 section in Menghua heavy haul railway is fine breccia group A filling. The subgrade filling at the bottom layer (thickness $1.9 \mathrm{~m}$ ) of the subgrade bed is $5 \%$ cement-stabilized expansive soil. The subgrade below the bottom layer of the subgrade bed is $3 \%$ cement content-stabilized expansive soil. Critical dynamic stress method [36] for long-term kinetic stability evaluation of subgrade was used to evaluate working performance. The main steps are as follows:

(1) Dynamic triaxial test is used to determine critical dynamic stress $\sigma_{c r s}$ of cement-stabilized soil as subgrade filling;

(2) Attenuation curves of the dynamic stress in the subgrade along the depth are tested or calculated to determine maximum dynamic stress $\sigma_{d f}$ at the foundation bed layer of the subgrade;

(3) Long-term dynamic stability of the subgrade is evaluated according to $\sigma_{c r s}$ and $\sigma_{d f}$ values, and concrete evaluation criteria are as follows:

Satisfy: $\sigma_{d f}<\sigma_{c r s}$

Do not satisfy: $\sigma_{d f}>\sigma_{c r s}$

Critical condition:

Change rules of dynamic stress along the subgrade depth under dynamic train load action of heavy haul railway are comprehensively analyzed mainly through theoretical calculation, standard recommended algorithm, and indoor model test data.
(1) Theoretical calculation. Transfer matrix method is used to calculate the subgrade stress of heavy haul railway, and the specific calculation process can be referred to in Literature [37].

(2) Standard recommended algorithm. Clause Explanation of Design Specifications of High-speed Railway (TB1062-2009) indicates that Boussinesq theoretical calculation is adopted for dynamic stress distribution excited by dynamic train load along the subgrade depth, and the specific calculation process can be referred to in Literature [38].

(3) Model test. With the help of the 1:1 subgrade fullscale model test built by the national railway subgrade laboratory in Central South University, dynamic stress values at different depths of the subgrade are acquired under a train speed of $120 \mathrm{~km} / \mathrm{h}$ when axle loads are 25 and $30 \mathrm{t}$.

The loading system comprises 5 groups of large-span rigidity counter-force beams, 10 sets of servo actuators, 5 groups of oil sources and controllers that can work independently, 1 condensing tower, and 1 set of MTS multichannel coordinated control system. Each actuator transfers the vibration load of the train to two neighboring pairs of fastening points through the dynamic load distribution system, and the input load time course of the actuator should be the superposition $\sigma_{d f}=\sigma_{c r s}$ of counterforce time courses of fastening points connected by the actuator. The superposition curves of the two pairs of fastening points are expressed as follows:

$$
Q(t)=2\left[F\left(t-L_{i} / 2 c\right)+F\left(t+L_{i} / 2 c\right)\right] \quad(0 \leq t \leq T)
$$

Then, the functional expression of actuator loading is:

$Q^{\prime}(t)=\left\{\begin{array}{cc}Q(t) & Q(t) \geq 0 \\ 0 & Q(t)<0\end{array}\right.$ 
where $F(t)$ is the counterforce of the fastening point and is expressed as:

$$
\begin{aligned}
& F(t)=a_{0}+a_{1} \cos (\omega t)+b_{1} \sin (\omega t)+b_{2} \cos (2 \omega t)+ \\
& b_{2} \sin (2 \omega t)+a_{3} \cos (3 \omega t)+b_{3} \sin (3 \omega t) \\
& b_{i}=\text { Mh } \omega
\end{aligned}
$$

where $L_{i}$ is the spacing between fastening points, $c$ is the train speed, $T$ is the action cycle of train load, $\omega$ is the train vibration frequency, $a_{0}$ is the static load of train wheel, $M$ is the unsprung mass of the train, and $h$ reflects the geometric irregular vector height under unstable road control conditions.

Fig. 10 shows that the change curves of dynamic stress along the subgrade depth acquired through the subgrade fullscale model test coincide with those in Literature [37] and [38], and their mutual reasonabilities can be verified. The maximum dynamic stress within the subgrade depth range of $0.6-1.9 \mathrm{~m}$ is $96 \mathrm{kPa}$, which is smaller than the critical dynamic stress $(148.8-233.1 \mathrm{kPa})$ of expansive soil stabilized with $5 \%$ cement content in the same position. The maximum dynamic stress within the subgrade depth range of $1.9-2.5 \mathrm{~m}$ is $30 \mathrm{kPa}$, which is smaller than the critical dynamic stress $(145.6-249.7 \mathrm{kPa})$ of expansive soil stabilized with $3 \%$ cement content in the same position. Thus, the application of cement-stabilized expansive soil as subgrade filling of heavy haul railway meets the long-term dynamic stability requirement with large affluence.

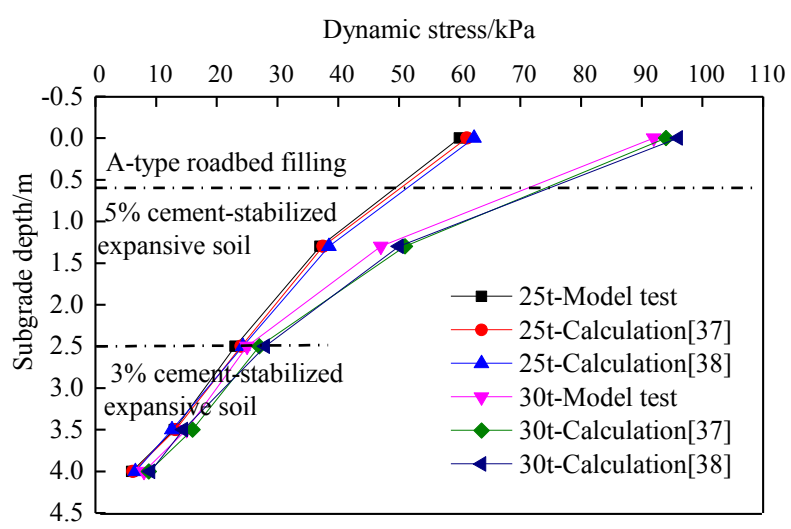

Fig. 10. Curves of dynamic stress along subgrade depth

\section{Conclusions}

The dynamic features of cement-stabilized expansive soil as subgrade filling were analyzed under different dynamic stress amplitudes, confining pressures, and vibration frequencies to explore its combination with the dynamic triaxial test. The following conclusions have been obtained:

(1) As a result of the cement solidification effect, the dynamic shear strength of expansive soil added with cement is significantly improved. The increasing amplitude of the dynamic shear strength of cement-stabilized expansive soil is most apparent as the confining pressure increases. This finding indicates that dynamic shear strengths of remolded plain expansive soil and cement-stabilized expansive soil are mainly related to soil properties and initial stress state.

(2) The change trends of accumulated plastic deformations of cement-stabilized expansive soil and remolded plain expansive soil with vibration times can be divided into stable, failure, and critical types. Critical dynamic stress has a favorable linear correlation with confining pressure. Under the same conditions, the critical dynamic stress of cement-stabilized expansive soil is larger than that of lime-stabilized expansive soil and cement containing coarse-particle filling.

(3) The increased rigidity amplitude of expansive soil after cement addition is large. The dynamic elasticity modulus of cement-stabilized expansive soil decreases as strain increases, but the situation for the damping ratio is the opposite. Their decrease and increase amplitudes reach the maximum values within a small strain range. The maximum dynamic elasticity modulus gradually increases as the confining pressure and frequency increase. Increasing frequency can elevate the maximum damping ratio, and the maximum damping ratio presents a decreasing trend when the confining pressure increases.

(4) The change rules of dynamic stress along the subgrade depth in the subgrade model test coincide well with the theoretical calculation. After the use of cement-stabilized expansive soil as subgrade filling of heavy haul railway, the critical dynamic stress of cement-stabilized expansive soil in the same position is considerably larger than the model test and theoretical calculation values. This finding indicates that the application of cement-stabilized expansive soil as subgrade filling of heavy haul railway can satisfy the working performance requirement under long-term train load action.

The dynamic features of cement-stabilized expansive soil of heavy haul railway combined with the dynamic triaxial test were studied in this paper. This study has an important reference value in acquiring dynamic parameters at the core layer on the subgrade bed of a heavy haul railway. In addition, this study can provide a theoretical reference for the promotion and application of cement-stabilized expansive soil in a heavy haul railway. Field vibration tests on dynamic characteristics of subgrade can be combined in future studies to further analyze the long-term working performance of cement-stabilized expansive soil as subgrade filling of heavy haul railway.

\section{Acknowledgements}

The authors are grateful for the support provided by the Science Foundation of China (Grant Nos. 51078358) and the High-Speed Rail Joint Fund Key Project of China (Grant No. U1134207).

This is an Open Access article distributed under the terms of the Creative Commons Attribution Licence

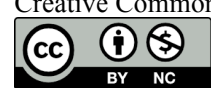




\section{References}

1. Lu, Z. H., Ma Y. F., Song L., et la. "Experimental Study on Fatigue Behavior of $8 \mathrm{~m}$ Low-height Reinforced Concrete Plate-girder of Heavy-haul Railway". Journal of Central South University (Science and Technology), 48(09), 2017, pp. 2550-2558.

2. Wu, Q. J., Li, Z. Q., Yu, L., et la. "Experimental Study on the Longterm Dynamic Characteristics of Heavy Haul Railway Tunnel Basement Structures". Journal of Vibration and Shock, 36(10), 2017, pp. 127-133+167.

3. Gong, K., Xiang, J., Yu C Y., "Effects of Track Stiffness on Freight Train Anti-derailment Safety Degree in Heavy-haul Railway". Journal of Southeast University (Natural Science Edition), 47(01), 2017, pp. 184-192.

4. Feng, H. P., Wang, Z. P., Chang, J. M., et al. "Experimental Study on Dynamic Wet Characteristics of Heavy haul Railway Bed". China Civil Engineering Journal, 48(S2), 2015, pp. 236-240.

5. Guo, K. M., Wang, X. D., Duan, C, L., "Thickness Design of Heavy Haul Railway Subgrade bed based on strength control method". Journal of Railway Science and Engineering, 14(01), 2017, pp. 5965.

6. Gao, M. M., Zheng, X. L., Yang, F., "Dynamic Performance Study of Track-bridge Transition Section for $30 \mathrm{t}$ Axle Load Heavy Haul Railway”. High Speed Railway Technology, 7(05), 2016, pp. 71$74+79$.

7. Seed, B., Martin, P. P., Lysmer, J., "Pore-water Pressure Changes During Soil Liquefaction". Journal of Geotechnical and Geoenvironmental Engineering, 1976, pp. 102(Proc. Paper\#12074).

8. Xie, Q. F., Liu, G. B., Fan, S. T, et al. "A Study of Dynamic Characteristics of the Saturated Remolded Clayey Silt under Circle Load". Hydrogeology and Engineering Geology, 44(01), 2017, pp. 78-83.

9. Luo, Q., Liu, G., Zhang, L., et al. "Characteristics of Cumulative Deformation Evolution State of Subgrade Filler under Cyclic Loading and Experimental Verification". Journal of the China Railway Society, 38(07), 2016, pp. 110-116.

10. Leng,W. M., Zhou, W. Q., Nie, R. S., et al. "Analysis of Dynamic Characteristics and Accumulative Deformation of Coarse- Grained Soil filling of Heavy- Haul Railway". Rock and Soil Mechanics, 37(03), 2016, pp. 728-736.

11. Taha, M. R., Taha, O. M. E., "Influence of Nano-material on the Expansive and Shrinkage Soil Behavior". Journal of Nanoparticle Research, 14(10), 2012, pp. 1-13.

12. Wu, J. H., Yang, S., "Experimental Study of Matric Suction Measurement and its Impact on Shear Strength under Dryingwetting Cycles for Expansive Soils". Rock and Soil Mechanics, 38(3), 2017, pp. 678-684.

13. Papagiannakis, A. T., Bin-Shafique, S., Lytton, R. L., "Retaining Structures in Expansive Clays". Geotechnical and Geological Engineering, 32(6),2014, pp. 1405-1414.

14. Li, Z. Q., Tang, C., Hu, R, L., et al. "Experimental research on expansion characteristics of Mengzi expansive soil with water, salt and acid immersion". Environmental Earth Sciences, 72(2), 2014, pp. 363-371.

15. Lin, B. T., Cerato, A. B., "Shear strength of shale weathered expansive soils along swell-shrink paths: analysis based on microscopic properties". Environmental Earth Sciences, 74(9), 2015, pp. 6887-6899.

16. Huang, B., Cheng, Z. L., Zhang, W., et al. "Expansion Model Test of Expansive Soil in Different Stress State". Soil Mechanics and Foundation Engineering, 52(2), 2015, pp. 57-67.

17. Tripathy, S., Kanakapura, S., Rao, S., "Cyclic Swell-Shrink Behaviour of a Compacted Expansive Soil". Geotechnical and Geological Engineering, 27(1), 2009, pp. 89-103.

18. Chowdhury, R. H., Azam, S., "Unsaturated Shear Strength Properties of a Compacted Expansive Soil from Regina, Canada". Innovative Infrastructure Solutions, 1(1), 2016, pp. 1-11.

19. Ozer, M., Ulusay, R., Isik, N. S., "Evaluation of Damage to Light Structures Erected on a Fill Material Rich in Expansive Soil". Bulletin of Engineering Geology and the Environment, 71(1),2012, pp. 21-36.
20. Tang, C. S,. Shi B,. Liu, C., "Study on Desiccation Cracking Behaviour of Expansive Soil". Journal of Engineering Geology, 20(05),2012, PP. 663-673.

21. Wang, Y. X., Guo, P. P., Shan, S. B., et al. "Study on Strength Influence Mechanism of Fiber-Reinforced Expansive Soil Using Jute". Geotechnical and Geological Engineering, 34(4), 2016, PP. 1079-1088.

22. Far, H., Flint, D., "Significance of Using Isolated Footing Technique for Residential Construction on Expansive Soils". Frontiers of Structural and Civil Engineering, 11(1), 2017, PP.123129.

23. Lin, B. T., Cerato, A. B., "Prediction of Expansive Soil Swelling Based on Four Micro-scale Properties". Bulletin of Engineering Geology and the Environment, 71(1), 2012, PP. 71-78.

24. Soundara, B., Robinson, R. G., "Hyperbolic Model to Evaluate Uplift Force on Pile in Expansive Soils". KSCE Journal of Civil Engineering, 21(3), 2017, PP. 746-751.

25. Phanikumar, B. R., Uma, Shankar, M., "Heave Studies on Fly AshStabilised Expansive Clay Liners". Geotechnical and Geological Engineering, 35(1), 2017, PP. 111-120.

26. Pitthaya, J., Nuttapong, N., Panich, V., et la. "Laboratory Investigations on the Swelling Behavior of Composite Expansive Clays Stabilized with Shallow and Deep Clay-cement Mixing Methods". Applied Clay Science, 148, 2017, PP. 83-94.

27. Zha, F. S., Cui, K. R., Liu, S. Y., et la. "Experimental Study on Cyclic Swell-shrink Behavior of Expansive soils". Journal of Hefei University of Technology (Natural Science), 32(3), 2009, P. 399 420 .

28. Ma, S. K., Zhao, N. F., Zhou, D., et la. "Characteristics study of long-term compressibility of Nanning expansive soil". Rock and Soil Mechanics, 34(08), 2013, pp. 2280-2286.

29. Zhuang, X. S., Peng, W. K., Wu, J. B. "Experimental Study on Strength of Limed- treated Expansive Clay". Highway Engineering. 42(05), 2017, pp. 1-5.

30. Fahoun, K., Aggour, M, S., Amini, F., "Dynamic properties of cohesive soil treated with lime". Journal of Geotechnical Engineering, ASCE. 122(5), 1996, pp. 382-389.

31. Petry, T. M., Little, D, N., "Review of stabilization of clays and expansive soils in pavements and lightly loaded structures-history, practice, and future". Journal of Materials in Civil Engineering, 14(6), 2002, pp. 447-460.

32. Wang, M. W., Qin, S., Li, J., et la. "Strengith of Unsaturated Limetreated Expansive Clay in Hefei ". Chinese Journal of Rock Mechanics and Engineering, 33(S2), 2014, pp. 4233-4238.

33. Mao, C., Qiu, Y. J. "Testing Study on Dynamic Properties of Expansive Soil and Improved Expansive Soil". Chinese Journal of Rock Mechanics and Engineering, 24(10), 2005, pp. 1783-1788.

34. Zhou, B, C., Bai, H., Kong, L, W., "Discussion on Critical Stress of Lime-treated Expansive Soil under cyclic loading". Rock and Soil Mechanics, 30(S2), 2009, pp. 163-168.

35. Yang, G. L., Qiu, M. M., He, X., et la. "Tests for Working Property of Water-proof Layer of Cutting Subgrade in Expansive Soil under Vibrating Load". Journal of Vibration and Shock, 35(05), 2016, pp. $1-7+20$.

36. Li, X., Cheng, Q. G., Zhang, J. C., et la. "Experimental Study on Dynamic Performance of Cement-improved Expansive Soil in High Speed Railway Subgrade in Wetting-drying Cycles". Railway Engineering, (06), 2016, pp. 99-103.

37. Liu, J. J., Ye, Q. Z., Song, X. G., et la. "Study on Stress and Deformation Analytic Method of Heavy Haul Railway Subgrade bed Based on Transfer-matrix". Railway Standard Design, 58(09), 2014, pp. 14-19.

38. Zhao, Y., Shang, Y, H., "Study on Dynamic Characteristics and Cumulative Deformation Law in High - speed Railway Subgrade under Dynamic Load". Railway Standard Design, 61(07), 2017,pp. 56-61. 